\title{
Polymerization of Aromatic Aldehydes. V. Cationic Cyclopolymerization of $o$-Vinylbenzaldehyde
}

\author{
Chuji Aso, Sanae Tagami, and Toyoki Kunitake \\ Department of Organic Synthesis, Faculty of Engineering, Kyushu University, \\ Fukuoka, 812, Japan. \\ (Received February 23, 1970)
}

\begin{abstract}
Polymerization of $o$-vinylbenzaldehyde was carried out at $0^{\circ} \mathrm{C}$ with $\mathrm{BF}_{3} \mathrm{OEt}_{2}$ catalyst. The polymers obtained as white powders were soluble in common organic solvents, and were not cleaved by treatment with dilute hydrochloric acid. The degree of polymerization was $20-30$. The polymer contained approximately $20 \%$ of the pendent vinyl group and 5\% of the pendent aldehyde group. The rest of the monomer unit was presumably the cyclized unit. On the basis of these structural data, a cationic propagation scheme of $o$-VBA was proposed, in which the neighboring aldehyde group reacted overwhelmingly with the growing cation to form a cyclic unit and the intramolecular cyclization of the neighboring vinyl group with the cation was competitive with the intermolecular propagation. This scheme was consistent with that expected from the cyclopolymerization schemes of $o$-divinylbenzene and $o$-phthalaldehyde.
\end{abstract}

KEY WORDS Cyclopolymerization/Cationic Polymerization/Ring Formation / Cyclopolymer / $o$-Vinylbenzaldehyde / Poly $(o$-Vinylbenzaldehyde) /

$o$-Vinylbenzaldehyde $(o$-VBA, I) possesses two types of the functional group which can undergo addition polymerization, and the selective polymerization of these functional groups is conceivably possible under appropriate conditions. In fact, the vinyl group polymerized selectively with a free radical initiator. ${ }^{1}$

On the other hand, both the vinyl and aldehyde groups are believed to participate in polymerization with cationic catalysts. Styrene and benzaldehyde copolymerized fairly readily with cationic catalysts and the copolymer of the approximately equimolar composition was obtained at high benzaldehyde feeds (eq 1)., ${ }^{2,3}$ Therefore, the vinyl and aldehyde groups of $o$-VBA, being located at the ortho position, are expected to undergo cyclopolymerization to form cyclopolymers as in eq 2 .

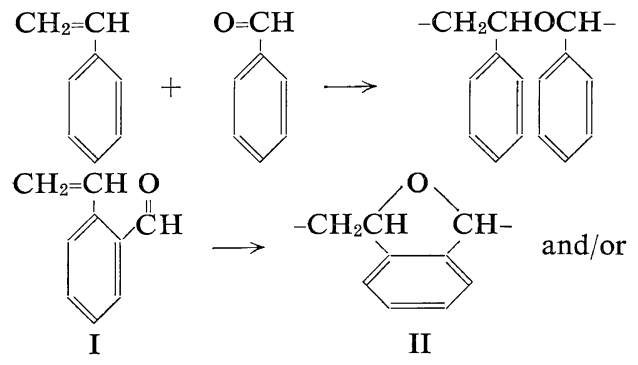

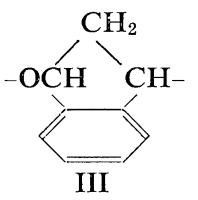

The cyclopolymerization of related monomers such as $o$-divinylbenzene and $o$-phthalaldehyde has been studied in some detail in these laboratories. ${ }^{4,5}$ Particularly noteworthy was the fact that, in spite of the lack of homopolymerizability of benzaldehyde, $o$-phthalaldehyde gave cyclopolymers with ease. $o$-Divinylbenzene showed a reactivity not very different from styrene, apart from partial formation of the cyclic structure. $o$-VBA lies structurally in between these two typical bifunctional monomers, and it is interesting to compare the polymerization behavior of $o$-VBA with those of $o$ divinylbenzene and $o$-phthalaldehyde.

\section{EXPERIMENTAL}

\section{Materials}

The monomer (o-VBA) was prepared from 3,4-dihydro-isoquinoline according to the procedure of Dale, et al., ${ }^{6}$ and preserved in a freezer at $-20^{\circ} \mathrm{C}$. Yield $55 \%$. Bp $50.3-50.8^{\circ} \mathrm{C}$ 
$(2.3 \mathrm{~mm})$. The purity estimated from a gas chromatogram was higher than $96 \%$.

Anal. Calcd for $\mathrm{C}_{9} \mathrm{H}_{8} \mathrm{O}: \mathrm{C}, 81.79 ; \mathrm{H}, 6.10$. Found: C, 81.78; H, 6.32. 2,4-Dinitrophenylhydrazone: $\mathrm{mp} 195-196^{\circ} \mathrm{C}$ (lit. ${ }^{6} \mathrm{mp} 197-198^{\circ} \mathrm{C}$ ).

Anal. Calcd for $\mathrm{C}_{15} \mathrm{H}_{12} \mathrm{~N}_{4} \mathrm{O}_{4}$ : C, 57.69; H, 3.87; N, 17.94. Found: C, 57.67; H, 4.02; $\mathrm{N}, 17.68$.

An NMR spectrum of $o$-VBA showed a formyl proton peak (singlet) at $10.18 \mathrm{ppm}$ and a complex multiplet at $7.0-8.0 \mathrm{ppm}$ due to phenyl protons $(\max 7.45 \mathrm{ppm})$ and a vinyl methine proton. The octet at 5.3-5.8 ppm was assigned to vinyl methylene protons $\left(\mathbf{H}_{\mathrm{a}}, \mathrm{H}_{\mathrm{b}}\right)$ coupled to the vinyl methine proton $\left(\mathrm{H}_{\mathrm{c}}\right): \mathrm{H}_{\mathrm{a}}, \delta 5.40 \mathrm{ppm}$, $J_{\mathrm{ac}}=8.3 \mathrm{~Hz}, J_{\mathrm{ab}}=1.5 \mathrm{~Hz} ; \mathrm{H}_{\mathrm{b}}, \delta 5.63 \mathrm{ppm}, J_{\mathrm{bc}}=$ $14.8 \mathrm{~Hz} ; \mathrm{H}_{\mathrm{c}}, \delta 7.2-7.8 \mathrm{ppm}$. The peak area ratio of formyl proton, phenyl proton + vinyl methine proton and vinyl methylene proton was $1: 5.4: 2.1$ in fair agreement with the calculated ratio of $1: 5: 2$.

1,3-Dimethylphthalan was prepared from $o$ phthalaldehyde in $40 \%$ yield according to the method of Nelken, et al., ${ }^{8}$ bp $57^{\circ} \mathrm{C}(3.5 \mathrm{~mm})$ [lit. $\left.{ }^{8} 122^{\circ} \mathrm{C}(50 \mathrm{~mm})\right]$.

$o$-VBA-diethylacetal was prepared from $o$-VBA and ethanol in the presence of $\mathrm{NH}_{4} \mathrm{Cl}$ using the method of Claisen. ${ }^{7}$ Bp $73-75^{\circ} \mathrm{C}(3 \mathrm{~mm})$. The structure of the acetal was confirmed by IR and NMR spectra.

$\left(\mathrm{C}_{2} \mathrm{H}_{5}\right)_{3} \mathrm{OBF}_{4}$ was prepared from $\mathrm{BF}_{3} \mathrm{O}\left(\mathrm{C}_{2} \mathrm{H}_{5}\right)_{2}$ and epichlorohydrin in ether by the method of Meerwein. ${ }^{9}$

$\mathrm{BF}_{3} \mathrm{OEt}_{2}$ was purified by distillation under nitrogen, and methylene chloride was purified by the usual procedure.

\section{Polymerization Procedures}

$o$-VBA, kept in a freezer, was added with a small amount of 2,6-di-t-butyl-p-cresol and redistilled just prior to polymerization. The polymerization was carried out in Schlenk-type ampoules under nitrogen. Given amounts of monomer and solvent were placed in an ampoule and a catalyst solution was added at the given polymerization temperature. After a predetermined period, polymerization was terminated by adding a small amount of pyridine and the reaction mixture was poured into $n$-hexane or methanol. The polymer was separated and purified by reprecipitation from benzene and methanol.

\section{Hydrolysis of Polymer}

A polymer sample $\left(\bar{M}_{n} 2180\right.$, No. 2 of Table I) $(90 \mathrm{mg})$ was dissolved in $1 \mathrm{ml}$ of benzene. To this solution was added $0.5 \mathrm{ml}$ of $1 \mathrm{~N}$ hydrochloric acid in ethanol and the mixture was kept at $60^{\circ} \mathrm{C}$ for $1.5 \mathrm{hr}$. A pale brown polymer $\left(\bar{M}_{n}\right.$ 2680) was recovered in $70 \%$ yield by precipitation in methanol. An IR spectrum of this polymer was quite similar to that of the original polymer, suggesting that the polymer remained mostly unchanged.

\section{Determination of Pendent Functional Groups in Polymer}

Pendent Aldehyde Group. A polymer sample was dissolved in benzene-ethanol and 2,4-dinitrophenylhydrazine in acidic $\left(\mathrm{H}_{2} \mathrm{SO}_{4}\right)$ ethanol was added, and the mixture was heated. The polymer was recovered by precipitation in methanol and purified by reprecipitation from benzene and methanol. By assuming that the aldehyde group in polymer reacted quantitatively with the hydrazine, the amount of the pendent aldehyde group was determined from elemental analysis of the dried polymer. Determination of the pendent aldehyde group was also carried out by infrared spectroscopy using poly $(o$-VBA) obtained by radical polymerization as reference. A calibration curve was prepared between the peak intensity at $1700 \mathrm{~cm}^{-1}$ and the concentration of the aldehyde unit of the reference polymer solution in carbon tetrachloride.

Pendent Vinyl Group. The pendent double bond in polymer was determined by bromination. About $0.1 \mathrm{~g}$ of a polymer sample was dissolved in $2-5 \mathrm{~m} l$ of chloroform and reacted with $0.5 \mathrm{ml}$ of a bromine solution $(2.3 \mathrm{~mol} / l$ in chloroform) at $-20^{\circ} \mathrm{C}$. After $30 \mathrm{~min}$ the reaction mixture was poured into methanol. The polymer separated was purified by reprecipitation from chloroform and methanol. The amount of pendent double bond was calculated from the elemental analytical data (carbon and hydrogen) of the product, by assuming quantitative bromination. The Wijs' method was also used for the determination of pendent vinyl groups as follows: about $0.1 \mathrm{~g}$ of a polymer sample was dissolved in $20 \mathrm{~m} l$ of carbon tetrachloride and 
titrated with $0.2 \mathrm{~N}$ acetic acid solution of $\mathrm{I}_{2}$ and $\mathrm{ICl}_{3}$.

Reaction of Monomer with $\left(\mathrm{C}_{2} \mathrm{H}_{5}\right)_{3} \mathrm{OBF}_{4}$

To $1.5 \mathrm{~g}(0.08 \mathrm{~mol})$ of $\left(\mathrm{C}_{2} \mathrm{H}_{5}\right)_{3} \mathrm{OBF}_{4}$ in $30 \mathrm{ml}$ of methylene chloride was dropwise added $8 \mathrm{~g}$ $(0.06 \mathrm{~mol})$ of $o$-VBA in $15 \mathrm{ml}$ of methylene chloride while stirring over a period of $3 \mathrm{~min}$, at $-20^{\circ} \mathrm{C}$ under nitrogen. Upon standing for $1 \mathrm{hr}$ at $0^{\circ} \mathrm{C}$, the reaction mixture was again cooled to $-20^{\circ} \mathrm{C}$ and $13.6 \mathrm{~g}(0.2 \mathrm{~mol})$ of sodium ethoxide in ethanol was added. The solution was filtered, washed with saturated aqueous sodium carbonate, and extracted with ether. After drying with anhydrous sodium sulfate, ether was evaporated and the residue distilled. The unreacted $o$-VBA was first recovered in $25 \%$ yield [bp $\left.50-51{ }^{\circ} \mathrm{C}(2 \mathrm{~mm})\right]$, and then the reaction product was isolated at $60-62^{\circ} \mathrm{C}(2 \mathrm{~mm})$. The purity of this reaction product was estimated from gas chromatography to be $95 \%$, and its IR and NMR spectra were identical with those of $o$-VBA-diethylacetal which was prepared from $o$-VBA and ethanol by the Claisen procedure. $^{7}$ The residue of distillation was a brownish viscous oil $(2.0 \mathrm{~g})$ which fractionated into the methanol-soluble (yield 5\%, $\bar{M}_{n}=730$ ) and methanol-insoluble (yield 20\%, $\bar{M}_{n}=1120$ ) fractions. The structure of the methanol-insoluble fraction was shown to be similar to that of poly $(o$-VBA) on the basis of IR spectrum, with $15 \mathrm{~mol} \%$ of the pendent vinyl group and an undetectable amount of the aldehyde group. Formation of the diethylacetal is believed to occur as follows

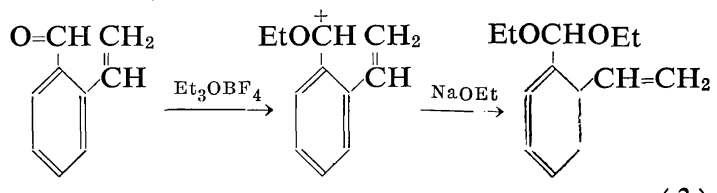

\section{Instruments}

The molecular weight of the polymer was measured with a vapor-pressure osmometer (Mechrolab Model $301 \mathrm{~A}$ ) at $37^{\circ} \mathrm{C}$ in benzene. Infrared and NMR spectra were obtained with a JASCO DS 301 spectrometer and a Varian A 60 spectrometer, respectively.

\section{RESULTS}

\section{Polymerization}

The polymerization results with $\mathrm{BF}_{3} \mathrm{OEt}_{2}$ catalyst are given in Table I. Polymerization

Table I. Cationic polymerization of $o$-VBA

\begin{tabular}{|c|c|c|c|c|c|c|c|c|c|}
\hline \multirow[b]{2}{*}{ No. } & \multirow{2}{*}{$\begin{array}{l}\text { Monomer } \\
\text { concn, } \\
\text { g/cc }\end{array}$} & \multirow[b]{2}{*}{ Solvent } & \multirow{2}{*}{\multicolumn{2}{|c|}{$\begin{array}{l}\text { Catalyst } \\
\text { concn, } \\
\text { mol } \%\end{array}$}} & \multirow{2}{*}{$\begin{array}{c}\text { Polymeriza- } \\
\text { tion } \\
\text { temp } \\
{ }^{\circ} \mathrm{C}\end{array}$} & \multirow{2}{*}{$\underset{\mathrm{hr}}{\mathrm{Time}}$} & \multirow{2}{*}{$\begin{array}{c}\text { Conver- } \\
\text { sion, } \\
\%\end{array}$} & \multicolumn{2}{|c|}{ Polymer } \\
\hline & & & & & & & & $\begin{array}{c}\mathrm{C}=\mathrm{C} \text { content } \\
\text { mol } \%\end{array}$ & $\begin{array}{c}\mathrm{C}=\mathrm{O} \text { content } \\
\text { mol } \%\end{array}$ \\
\hline 1 & 0.10 & $\mathrm{CH}_{2} \mathrm{Cl}_{2}$ & $\mathrm{BF}_{3} \mathrm{OEt}_{2}$ & 5.0 & 30 & 14 & 43.7 & $18.7^{\mathrm{e}}$ & \\
\hline 2 & 0.26 & $" 1$ & " & 5.0 & 0 & 15 & $27.1^{\mathrm{a}}$ & $21.2^{\mathrm{e}}, 16.3^{\mathrm{f}}$ & \\
\hline 3 & 0.24 & " & " & 5.4 & $4-20$ & 24 & 16.1 & $15.6^{\mathrm{e}}$ & \\
\hline 4 & 0.20 & $\mathrm{C}_{6} \mathrm{H}_{5} \mathrm{CH}_{3}$ & " & 5.0 & 0 & 14 & 8.0 & $20.0^{\mathrm{c}}$ & \\
\hline 5 & 0.50 & $\mathrm{CH}_{2} \mathrm{Cl}_{2}$ & " & 2.4 & 20 & 17.5 & $23.7 \mathrm{~b}$ & $9-14^{\mathrm{g}}, 16.3^{\mathrm{f}}$ & $4.0^{\mathrm{h}}$ \\
\hline 6 & 0.50 & $" 1$ & " & 2.4 & 0 & 16 & $30.4^{\mathrm{c}}$ & & $5.1^{\mathrm{h}}$ \\
\hline 7 & 0.22 & $"$ & " & 6.0 & 0 & 20 & 33.8 & $24-33 \mathrm{~g}$ & $5.5^{\mathrm{h}}$ \\
\hline 8 & 0.20 & " & " & 5.0 & 0 & 24 & 27.0 & $10-20 \mathrm{~g}$ & $4.9^{\mathrm{i}}$ \\
\hline 9 & 0.10 & $\mathrm{C}_{2} \mathrm{H}_{5} \mathrm{NO}_{2}$ & " & 5.0 & 0 & 15 & 15.0 & & $4.2^{\mathrm{i}}$ \\
\hline 10 & 0.10 & $\mathrm{CH}_{2} \mathrm{Cl}_{2}$ & $\mathrm{Et}_{3} \mathrm{OBF}_{4}$ & 5.0 & 0 & 17 & $24.2^{\mathrm{d}}$ & $11-35 \mathrm{~g}$ & $4.0^{\mathrm{i}}$ \\
\hline $\begin{array}{l}\mathrm{d} \\
\mathrm{e}\end{array}$ & $\begin{array}{l}\bar{M}_{n}=2180 . \\
\bar{M}_{n}=3650, \\
\text { Softening p } \\
\bar{M}_{n}=2520 . \\
\text { By Wijs' } \\
\text { By bromina } \\
\text { By NMR } \mathrm{n} \\
\text { By hydrazo } \\
\text { By IR metr }\end{array}$ & $\begin{array}{l}\text { oftening } p \\
\text { nt } 152-16 \\
\text { hod. } \\
\text { on. } \\
\text { thod. } \\
\text { method. } \\
\text { d. }\end{array}$ & $\begin{array}{l}\text { ooint } 163 \\
0^{\circ} \mathrm{C}, \mathrm{Ana}\end{array}$ & $\begin{array}{l}170^{\circ} \mathrm{C} \\
\text { Calc }\end{array}$ & $\begin{array}{l}\text { C. } \\
\text { lcd for }\left(\mathrm{C}_{9} \mathrm{H}\right.\end{array}$ & : & $9 ; \mathrm{H}$ & 10, Found: & $1.47, \mathrm{H}, 6.39$. \\
\hline
\end{tabular}


occurred readily at around $0^{\circ} \mathrm{C}$, but was much slower at $-78^{\circ} \mathrm{C}$. The polymer was a white to yellowish-white powder and soluble in common organic solvents such as benzene and carbon tetrachloride. The degree of polymerization was $20-30$. The polymer presumably consists of the cyclized (II, III) and uncyclized (IV, V) units.
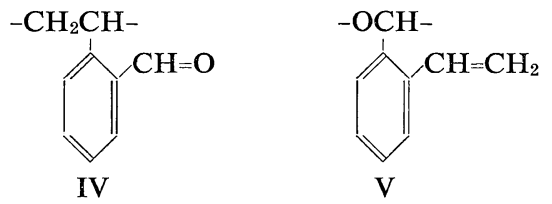

From hydrolysis data the polymer is considered not to contain ready-to-hydrolyze sequences of the acetal linkage, although absorption due to the ether linkage was pronounced at $960-1130 \mathrm{~cm}^{-1}$ in the IR spectrum. The amounts of the pendent aldehyde group determined by the hydrazone method were 4-5\% (Table I). Accordingly, the amount of the repeat unit IV is $4-5 \%$. Since the degree of polymerization was $20-30$, it is possible that the aldehyde group is located only at the chain end. The amount of the pendent vinyl group (i.e., the amount of V) was shown by the bromination method or the Wijs' method to be $15-20 \%$.

These chemical data show that the polymer approximately consists of $75 \%$ of unit II and/or III, 5\% of unit IV and 20\% of unit V.

\section{Polymer Spectra}

Figure 1 shows IR spectra of monomer (a), a polymer obtained with $\mathrm{BF}_{3} \mathrm{OEt}_{2}(\mathrm{~b})$, and 1,3-dimethylphthalan (c). The radical polymerization of $o$-VBA was concluded to proceed exclusively via the vinyl group, as mentioned elsewhere, ${ }^{1}$ and the polymer can be used as reference in determining the amount of the pendent aldehyde group in other polymers. The polymer obtained with $\mathrm{BF}_{3} \mathrm{OEt}_{2}$ contains little aldehyde group (Figure 1b), and its amount was determined to be $4-5 \%$ from a comparison of the IR peak intensity at $1700 \mathrm{~cm}^{-1}$ with that of the radical polymer. This result agreed closely with those determined by the hydrazone method.

The vinyl peak at $1627 \mathrm{~cm}^{-1}$ was very weak even in the monomer spectrum and it was not detected in the polymer spectra. The $\mathrm{C}-\mathrm{H}$ out-

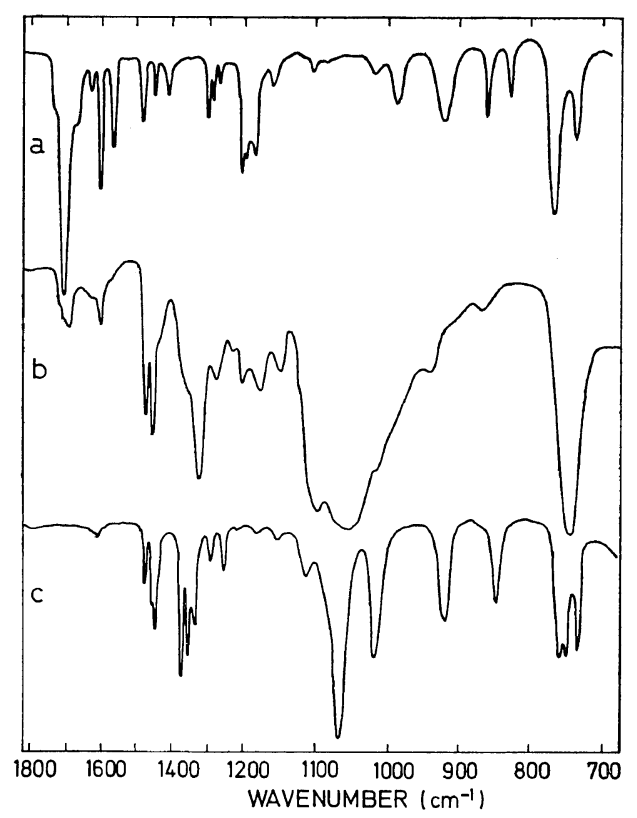

Figure 1. Infrared spectra of (a) $o-\mathrm{VBA}$ (neat), (b) poly $(o$-VBA) (KBr disk), and (c) 1,3-dimethylphthalan (neat).

of-plane bending peaks characteristic of the vinyl group (920 and $980 \mathrm{~cm}^{-1}$ for the monomer) decreased considerably in the polymer spectrum. These IR data indicate that the polymer contains considerable amounts of the cyclic structure (II and/or III). Although it is difficult to distinguish between structure II and III from the IR data, it is to be noted that the ether peak region $\left(1000-1100 \mathrm{~cm}^{-1}\right)$ in the spectrum of 1,3-dimethylphthalan (Figure 1c) is similar in shape to that $\left(960-1130 \mathrm{~cm}^{-1}\right)$ of the polymer (Figure 1b).

NMR spectroscopic data support the polymer structure inferred on the basis of the IR data. Figure 2 shows NMR spectra of the polymer and 1,3-dimethylphthalan. The polymer (Figure 2a) does not possess an aldehyde proton peak, while this peak is observed for both of $o$-VBA monomer $(10.18 \mathrm{ppm})$ and the radical polymer $(8.8-9.8 \mathrm{ppm}){ }^{1} \quad$ A broad peak at $6.6-7.7 \mathrm{ppm}$ (peak A) in the polymer can be assigned to overlapping of the aromatic proton and the vinyl methine proton. Peak B $(4.5-6.0 \mathrm{ppm})$ can be attributed to the vinyl methylene proton and the methine proton adjacent to oxygen. 


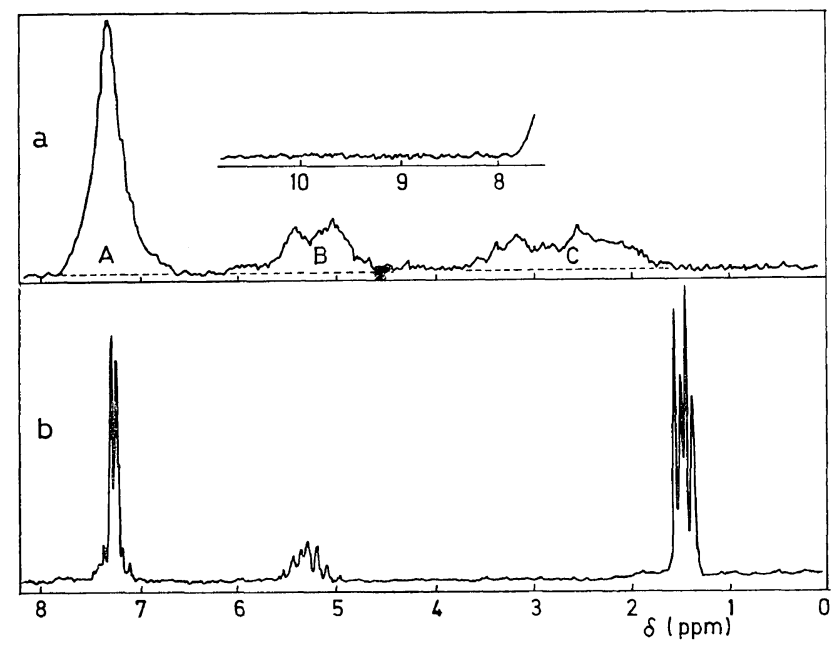

Figure 2. NMR spectra of (a) poly $\left(o\right.$-VBA) (in $\mathrm{CDCl}_{3}$ ), and (b) 1,3-dimethylphthalan (in $\mathrm{CCl}_{4}$ ).

Table II. Cationic copolymerization results of $o-\mathrm{VBA}^{\mathrm{a}}$

\begin{tabular}{|c|c|c|c|c|c|c|c|c|c|}
\hline No. & Comonomer & $\begin{array}{l}o \text {-VBA in } \\
\text { mononers, } \\
\text { mol } \%\end{array}$ & $\begin{array}{l}\text { Monomer } \\
\text { concn, } \\
\text { g/cc }\end{array}$ & $\begin{array}{l}\text { Catalyst } \\
\text { concn, } \\
\text { mol } \%\end{array}$ & $\begin{array}{c}\text { Polymeriza- } \\
\text { tion } \\
\text { temp, } \\
{ }^{\circ} \mathrm{C}\end{array}$ & $\underset{\mathrm{hr}}{\text { Time }}$ & $\begin{array}{l}\text { Conver- } \\
\text { sion, } \\
\%\end{array}$ & $\begin{array}{c}o \text {-VBA } \\
\text { units in } \\
\text { copolymer, } \\
\text { mol } \%\end{array}$ & $\begin{array}{c}\mathrm{C}=\mathrm{Cd} \\
\text { content, } \\
\text { mol } \%\end{array}$ \\
\hline 1 & Styrene & 25.2 & $0.46^{b}$ & 5.0 & 0 & 0.2 & 69.4 & 34.3 & - \\
\hline 2 & Styrene & 49.7 & $0.36^{b}$ & 1.0 & 0 & 12.5 & 43.5 & 52.8 & 23 \\
\hline 3 & Styrene & 47.0 & $0.19^{\mathrm{c}}$ & 5.0 & 0 & 15.5 & 64.8 & 43.5 & 21 \\
\hline 4 & Styrene & 63.9 & 0.293 & 5.0 & 0 & 15.5 & 77.3 & 61.8 & 23 \\
\hline 5 & Styrene & 47.8 & $0.65^{b}$ & 5.0 & -78 & 50 & 2.6 & 51.8 & 60 \\
\hline 6 & Benzaldehyde & 55.8 & $0.20^{\mathrm{b}}$ & 2.5 & 0 & 16 & 3.2 & 100 & - \\
\hline
\end{tabular}

a Catalyst, $\mathrm{BF}_{3} \mathrm{OEt}_{2}$.

b Solvent, $\mathrm{CH}_{2} \mathrm{Cl}_{2}$.

c Solvent, $\mathrm{C}_{6} \mathrm{H}_{5} \mathrm{CH}_{3}$.

d Content of pendent double bond $(\mathrm{C}=\mathrm{C})$ against the total $o$-VBA unit.

The latter proton corresponds to the methine proton peak of 1,3-dimethylphthalan at 4.7$5.4 \mathrm{ppm}$ (Figure 2b). A broad peak at 1.5$3.7 \mathrm{ppm}$ (peak C) can be assigned to the saturated methylene proton. From the relative peak area, the content of the uncyclized unit $\mathrm{V}$ may be estimated as follows

$$
\text { Unit } \mathrm{V}(\text { in } \mathrm{mol} \%)=\frac{4 \mathrm{~A}-4(\mathrm{~B}+\mathrm{C})}{\mathrm{A}+\mathrm{B}+\mathrm{C}} \times 100
$$

This method, however, was not very precise as indicated in the Table because the NMR peaks were broad. Therefore, the chemical methods were considered more reliable.

\section{Cationic Copolymerization}

Copolymerizations of $o$-VBA with styrene and benzaldehyde were conducted with $\mathrm{BF}_{3} \mathrm{OEt}_{2}$ catalyst. The results are given in Table II. In the copolymerization with benzaldehyde the elemental analysis of the product was close to that of the $o$-VBA homopolymer. However, the IR spectrum possessed a peak characteristic of the benzaldehyde unit at $700 \mathrm{~cm}^{-1}$, and, therefore, a sraall amount of benzaldehyde may be incorporated into polymer. The copolymerization with styrene proceeded smoothly, and the copolymer compositions were fairly close to the monomer feed ratios. The ratio of structural unit $\mathrm{V}$ to the $o$-VBA unit in the copolymer 
was somewhat greater than that in the $o$-VBA homopolymer. The content of $\mathrm{V}$ was particularly high at $-78^{\circ} \mathrm{C}$.

\section{DISCUSSION}

\section{Intramolecular Cyclization Scheme}

The cationic propagation scheme of $o$-VBA can be inferred from the present data as well as from the cationic polymerization results of $o$-divinylbenzene and $o$-phthalaldehyde previously obtained in these laboratories. In the cationic propagation of $o$-divinylbenzene the intramolecular cyclization (eq 5) was competitive with the intermolecular addition of VIII to another $o$-divinylbenzene molecule. The presence of approximately 20\% of the pendent vinyl group in poly $(o-\mathrm{VBA})$ suggests that the intramolecular cyclization of the cationic intermediate IX (eq 6a) is competitive with the intermolecular monomer addition (eq $6 \mathrm{~b}$ ) as in the cationic polymerization of $o$-divinylbenzene. The increase in the content of the pendent vinyl group in the copolymerization of $o$-VBA with styrene as compared with the homopolymerization indicates that facile addition of styrene to IX competed with the intramolecular cyclization, and that the uncyclized species IX is a discrete intermediate.
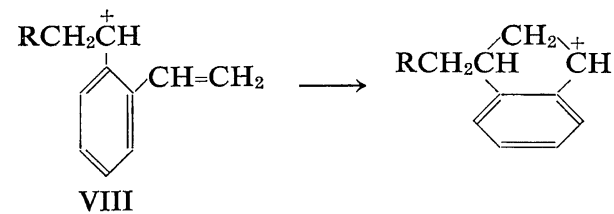

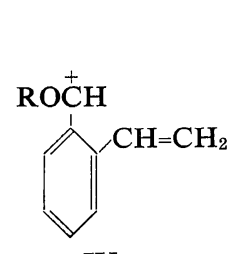

IX

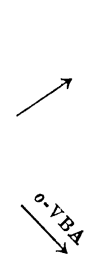

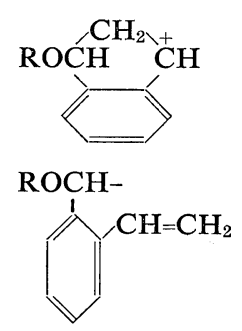

(6a)

(6b)
Previously we showed that the cationic propagation of $o$-phthalaldehyde proceeded through an intermediate $X$ in which the carbonium ion is strongly interacting with the neighboring aldehyde (eq 7), or through a concerted addition of the two aldehyde groups. ${ }^{5 a}$ Polyphthalalde- hyde obtained was completely cyclized. A similar situation may arise when the vinyl group of $o$-VBA first reacts with the growing cation $\mathrm{R}^{+}$ (eq 8). The subsequent facile cyclization can explain the very small amount of the pendent aldehyde group left.

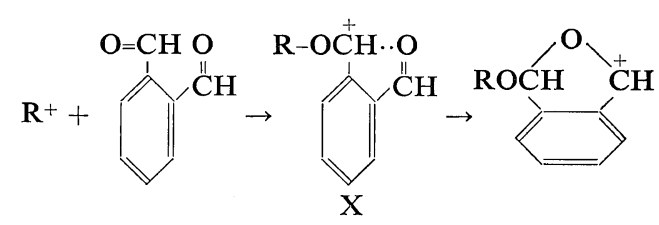

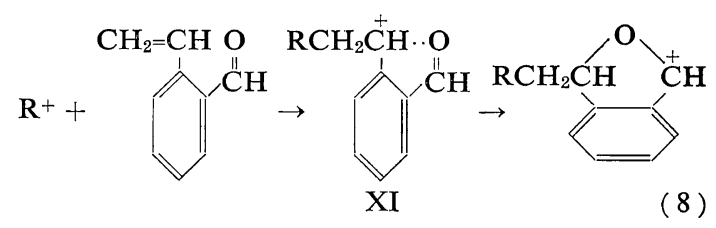

Considering that $o$-phthalaldehyde ${ }^{5}$ and $o$-formylphenylacetaldehyde ${ }^{10}$ polymerized readily with almost $100 \%$ cyclization, the aromatic aldehyde group appears to react with particular ease with the adjacent carbonium ion to form the five- or six-membered ring. This must be also true for the cationic polymerization of $o$-VBA.

Thus it is concluded that the cationic cyclization of $o$-VBA follows different schemes, depending on which of the functional groups first reacts with the cation.

\section{Intermolecular Propagation Scheme}

The nature of the growing cation is crucial in determining how the incoming monomer reacts. The following four structures can be conceived as the terminal carbonium ion.
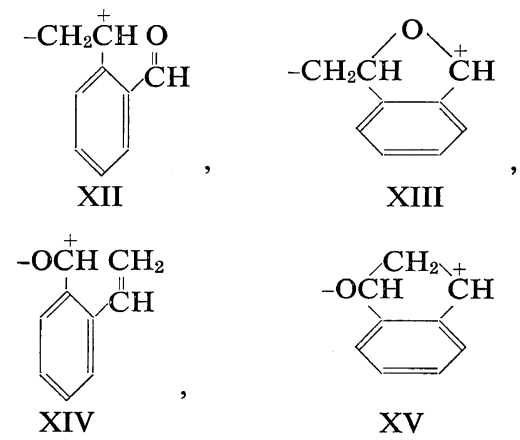

However, structure XII was probably insignificant because the content of the pendent aldehyde 
group was quite small.

Considering that $r_{1}=1 / 3.7$ and $r_{2}=0$ in the cationic copolymerization of styrene $\left(\mathrm{M}_{1}\right)$ and benzaldehyde $\left(\mathrm{M}_{2}\right)\left(\mathrm{BF}_{3} \mathrm{OEt}_{2}, 0^{\circ} \mathrm{C}\right.$, toluene $),{ }^{2}$ the styryl-cation-like intermediate $\mathrm{XV}$ would react with the aldehyde group of $o$-VBA in preference to the vinyl group and the reaction of cation XIV with the aldehyde group of $o$ VBA should be very difficult. The latter reasoning is supported by the fact that the attempted acid hydrolysis did not lead to chain scission which should occur readily with the vulnerable acetal linkage formed by the reaction of XIV with the aldehyde group.

Structure $\mathrm{XV}$ resembles the indenyl cation more closely than it does the styryl cation. The relative reactivity of benzaldehyde and styrene toward the indenyl cation can be estimated from the reactivity ratios $r_{1}\left(p=k_{\text {ind }}{ }^{+}\right.$ind $/ k_{\text {ind }}{ }^{+}$benz $)$of indene $\left(\mathrm{M}_{1}\right)$ and benzaldehyde $\left(\mathrm{M}_{2}\right)$ and $r_{1}$ $\left(q=k_{\text {ind }}{ }^{+}{ }_{\text {ind }} / k_{\text {ind }}{ }^{+}{ }_{\text {sty }}\right)$ of indene $\left(\mathrm{M}_{1}\right)$ and styrene $\left(\mathrm{M}_{2}\right)$ by using eq 9 .

$$
\frac{k_{\text {ind }}{ }^{+} \text {benz }}{k_{\text {ind }}{ }^{+} \text {sty }}=\frac{q}{p}
$$

The available reactivity data are $p=0.38$

$\left(\mathrm{BF}_{3} \mathrm{OEt}_{2},-78^{\circ} \mathrm{C}\right.$, toluene $)$ and $q=3.7\left(\mathrm{BF}_{3} \mathrm{OEt}_{2}\right.$, $30^{\circ} \mathrm{C}$, ethylene dichloride). ${ }^{11}$ By assuming the temperature change of the reactivity ratio is small, the indenyl cation is ten times more reactive with benzaldehyde than with styrene $(q / p=10)$. Thus, the aldehyde group of $o$-VBA can be considered to be much more reactive toward $\mathrm{XV}$ than the vinyl group.

From the reactivity data mentioned above and from the fact that $o$-vinylbenzaldehyde diethylacetal was obtained selectively as a $1: 1$ telomer from $o$-VBA and $\mathrm{Et}_{3} \mathrm{OBF}_{4}$ (see the experimental section), it is probable that the polymerization starts from the aldehyde group preferentially. Then the uncyclized intermediate (XIV) reacts with the neighboring vinyl group (eq 6a) or with the vinyl group of $o$-VBA (eq 11 ), and the cyclic intermediate $X V$ will react with the aldehyde group of $o$-VBA more readily (eq 12).

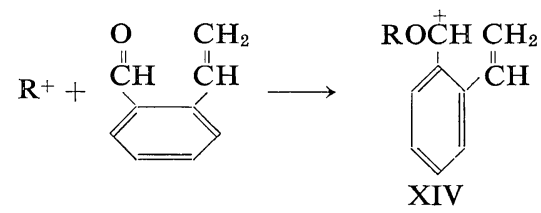

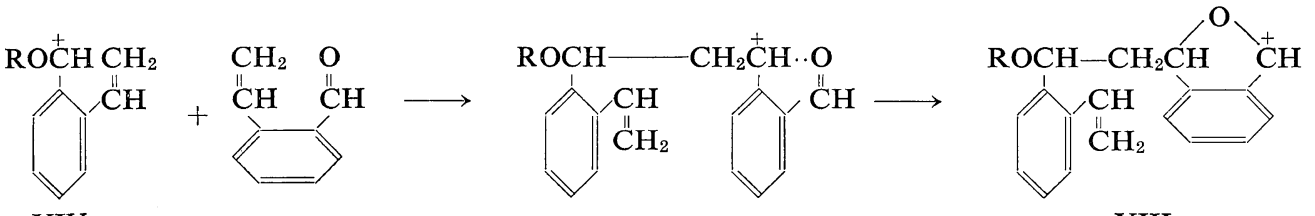

XIII

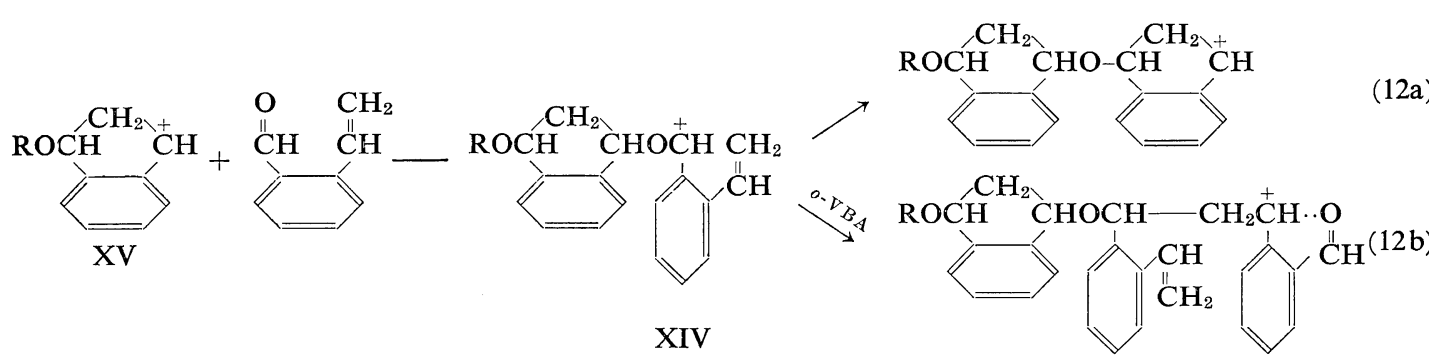

The cyclization in eq 11 should be almost complete, whereas the cyclization of XIV in eq 12 is not complete, as described above. Accordingly, the pendent vinyl group in polymer may be formed by the routes of eq 11 and $12 \mathrm{~b}$. The terminal unit XIII in eq 11 should be able to react with both of the vinyl and aldehyde groups of $o$-VBA. That is, if it reacts exclusively with the vinyl group, the pendent vinyl group will not be formed thereafter. Therefore, the polymer must contain acetal linkages of the following type. Considering the resistance of polymer toward acid hydrolysis, structure XVI may be more probable than XVII. 


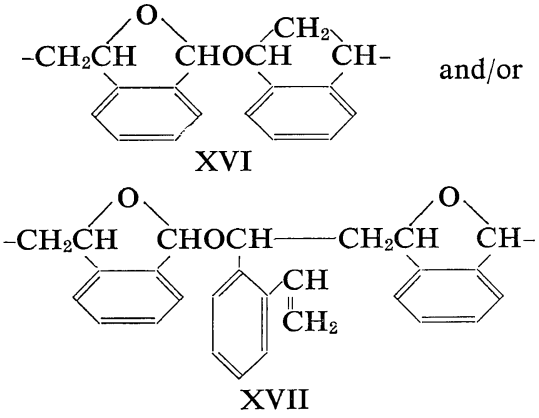

In conclusion, $o$-VBA polymerized readily with the cationic catalyst to give polymers consisting of the cyclic units (75\%) and the uncyclized unit having the pendent vinyl group ( 20\%). The content of the pendent aldehyde group was very small $(\sim 5 \%)$. In the previous studies a stepwise scheme was proposed for the cationic propagation of $o$-divinylbenzene, and the intermediate or concerted scheme for that of $o$-phthalaldehyde. $o$-VBA monomer possesses structural characteristics common to both of these monomers, and the polymerization results of $o$-VBA could be reasonably explained by assuming that either of these two cyclization schemes was operating, depending on the structure of the growing cation formed.

\section{REFERENCES}

1. C. Aso, S. Tagami, and T. Kunitake, Abstracts, The 17th SPSJ Symposium on macromolecules Ehime, Japan, Oct. 22-24, 1968, p 355.

2. C. Aso, S. Tagami, and T. Kunitake, Kobunshi Kagaku (Chem. High Polymers), 23, 63 (1966).

3. R. Raff, J. L. Cook, and B. V. Etting, J. Polym. Sci., Part A, 3, 3511 (1965).

4. a) C. Aso and R. Kita, Kogyo Kagaku Zasshi (J. Chem. Soc. Japan, Ind. Chem. Sect.), 68, 707 (1965).

b) C. Aso, T. Kunitake, and R. Kita, Makromol Chem., 97, 31 (1966).

5. a) C. Aso, S. Tagami, and T. Kunitake, J. Polym. Sci., Part A-1, 7, 497 (1969).

b) C. Aso and S. Tagami, Macromolecules, 2, 414 (1969).

6. J. Dale, L. Starr, and C. W. Strobel, J. Org. Chem., 26, 2225 (1961).

7. L. Claisen, Ber., 40, 3903 (1907).

8. F. Nelken and H. Simons, Ber., 41, 986 (1908).

9. H. Meerwein, E. Battenberg, H. Gold, E. Pfeil, and G. Willfang, J. Prakt. Chem., 154, 83 (1939).

10. C. Aso and S. Tagami, unpublished.

11. A. Mizote, T. Tanaka, T. Higashimura, and S. Okumura, J. Polym. Sci., Part A-1, 4, 869 (1966). 